\title{
Uptake of Fructose by the Sorbitol Phosphotransferase of Escherichia coli $\mathrm{K} 12$
}

\author{
By M. C. JONES-MORTIMER AND H. L. KORNBERG \\ Department of Biochemistry, University of Cambridge, \\ Tennis Court Road, Cambridge CB2 I $Q W$
}

(Received I3 May 1976)

\begin{abstract}
SUMMARY
Strains of Escherichia coli that are unable to grow on fructose because they lack the phosphoenolpyruvate:fructose phosphotransferases specified by $p t s F$ and $p t s X$ mutate to grow on media containing fructose as sole carbon source, but do not regain the function of either of the missing phosphotransferases. Instead, fructose is taken up and phosphorylated to fructose 6-phosphate by a phosphoenolpyruvate: sorbitol phosphotransferase which, in wild-type cells, is induced by sorbitol but not by fructose, but which is constitutively expressed in these mutants. The regulatory gene $\operatorname{srlC}$ controlling enzymes of sorbitol uptake and catabolism has been located on the $E$. coli genome as part of the linkage group cysI srlC attI86 pheA.
\end{abstract}

\section{INTRODUCTION}

Fructose normally enters Escherichia coli by two distinct routes, A and B in Fig. I (Ferenci \& Kornberg, 1974; Jones-Mortimer \& Kornberg, 1974). Both routes require the activity of the phosphotransferase system (Kundig, Ghosh \& Roseman, 1964), in which the phosphate group of phosphoenolpyruvate is enzymically transferred, initially to a small histidine-containing protein HPr. The phospho-HPr thus formed can then donate that phosphate group to fructose in one of two ways. In an enzymic reaction characterized by its high affinity for fructose $\left(K_{\mathrm{m}}<10^{-4} \mathrm{M}\right)$, fructose I-phosphate is formed (Fraenkel, I968; Ferenci \& Kornberg, I97I); the gene specifying this enzyme, designated $p t s F$, has been located on the $E$. coli linkage map at minute $4 \mathrm{I}^{\cdot} 5$ (Jones-Mortimer \& Kornberg, 1974). On the other hand, mutants that lack this high-affinity system for the uptake and phosphorylation of fructose can still grow on fructose, albeit in a manner strongly dependent on the concentration of the sugar present in the growth medium. Under these conditions, fructose 6-phosphate arises from the transfer of phosphate from phospho-HPr to fructose (Ferenci \& Kornberg, 1974). This system, characterized by its low affinity for fructose $\left(K_{\mathrm{m}}>10^{-3} \mathrm{M}\right)$, is specified by a gene, designated $p t s X$, that has been located on the $E$. coli linkage map at minute 36.5 (Jones-Mortimer \& Kornberg, 1974, 1976). It is likely that the normal physiological role of this system is to participate in the uptake of glucose, glucosamine and mannose by $E$. coli (Curtis \& Epstein, 1975; Kornberg \& Jones-Mortimer, 1974) rather than in the utilization of fructose. However, under conditions of batch culture of $E$. coli, where growth substrates are usually supplied at 5 to Io $\mathrm{mM}$, mutants that lack the high-affinity uptake system for fructose grow readily on fructose by taking up this sugar via the PtsX system. Mutants that lack only this system $\left(p t s F^{+} p t s X\right)$ grow on fructose in a manner indistinguishable from that of wild-type cells; mutants that lack both systems ( $p t s F p t s X$ ) do not grow even on high concentrations of fructose, and do not take up this sugar when supplied at either 0.1 or $5 \mathrm{mM}$ (Kornberg, 1972). 
Table I. Escherichia coli strains used in this work

\begin{tabular}{|c|c|c|}
\hline Strain no & Genetic markers & Reference and source \\
\hline KLI6.2I & Hfr ptsFI pts XI kdgR & Ferenci \& Kornberg (197I) \\
\hline JM463 & $\mathrm{F}^{-}$fpk galT lac pro metB cysI his str uhp ${ }^{\mathrm{c}}$ & Jones-Mortimer \& Kornberg (1974) \\
\hline JM474 & $\mathrm{F}^{-}$pts $X I \mathrm{kdg} R^{\mathrm{c}}$ fpk galT lac pro metB cysI str uhp ${ }^{\mathrm{c}}$ & KLI6.2I $\times$ JM463 $\rightarrow$ His $^{+}$ \\
\hline JM477 & $\mathrm{F}^{-}$ptsFI gnd kga leu str & Jones-Mortimer \& Kornberg (1974) \\
\hline JM485 & Hfr ptsFI pts XI kdgR $R^{\mathrm{c}}$ srlCI & KLI6.2 I (fructose positive) \\
\hline JM486 & $\mathrm{F}^{-}$ptsF2 ptsXI kdgR fpk galT lac pro metB cysI str uhp ${ }^{\mathrm{c}}$ & $\begin{array}{l}\text { JM474 (fructose resistant on } \\
\text { glycerol) }\end{array}$ \\
\hline JM733 & Hfr fda $^{\text {ts }}$ hisgnd ${ }^{\Delta}$ galbio $^{\Delta}$ & Jones-Mortimer \& Kornberg (1976) \\
\hline JM737 & Hfr pts $X 2$ fda $^{\text {ts }}$ hisgnd $^{\Delta}$ galbio $^{\Delta}$ & $\begin{array}{l}\text { JM733 (glucosamine resistant on } \\
\text { glycerol); Jones-Mortimer \& } \\
\text { Kornberg (1976) }\end{array}$ \\
\hline JM739 & $\mathrm{F}^{-}$ptsFI ptsX2 gnd leu str & Pr.JM737 $\times$JM477 $\rightarrow \mathrm{Kga}^{+}$ \\
\hline JM759 & Hfr ptsF 3 pts X2 fdats hisgnd ${ }^{\Delta}$ galbio $^{\Delta}$ & JM737 (fructose resistant on glycerol) \\
\hline JM760 & $\mathrm{F}^{-}$ptsF2 pts $X I \mathrm{kdg} R^{\mathrm{c}}$ fpk galT lac srlC2 pro met $B$ cysI str & JM486 (fructose positive) \\
\hline Jм763 & Hfr ptsF3 pts $X 2$ fda ${ }^{\text {ts }}$ hisgnd $^{\Delta}$ galbio $^{\Delta}$ srlA & $\begin{array}{l}\text { JM759 (sorbitol resistant on } \\
\text { glycerol); Jones-Mortimer \& } \\
\text { Kornberg (I976) }\end{array}$ \\
\hline JM78I & Hfr ptsF $F_{3}$ pts $X_{2}$ fda $^{\text {ts }}$ hisgnd $^{\Delta}$ galbio $^{\Delta}$ srlC $_{3}$ & JM759 (fructose positive) \\
\hline JM784 & Hfr ptsF 3 pts $X_{2}$ fda $^{\text {ts }}$ hisgnd ${ }^{\Delta}$ galbio $^{\Delta}$ srlC 3 srlA & JM78I (sorbitol resistant on glycerol) \\
\hline JM794 & $\mathrm{F}^{-}$ptsF2 pts XI kdgR ${ }^{\mathrm{c}}$ fpk galT lac pro metB cysI srlC4 str & JM486 (fructose positive) \\
\hline JM795 & $\mathrm{F}^{-}$ptsF2 pts $X I \mathrm{kdg} R^{\mathrm{c}}$ fpk galT lac pro metB cysI srlC 5 str & JM486 (fructose positive) \\
\hline JM803 & Hfr ptsF3 pts $X_{2}$ fda $^{\text {ts }}$ hisgnd $^{\Delta}$ galbio $^{\Delta}$ srlC $_{3}$ ptsI & $\begin{array}{l}\text { JM78I ( } N \text {-acetylglucosamine and } \\
\text { mannitol resistant on lactate) }\end{array}$ \\
\hline JMI058 & Hfr ptsF3 ptsX2 fda $^{\text {ts }}$ hisgnd ${ }^{\Delta}$ galbio $^{\Delta}$ mtlA & $\begin{array}{l}\text { JM759 (mannitol resistant on } \\
\text { glycerol) }\end{array}$ \\
\hline JMI069 & Hfr pheA (186) & $\begin{array}{l}\text { I86 lysogen of KAI97 (Hoekstra et } \\
\text { al., 1974) }\end{array}$ \\
\hline JMI072 & 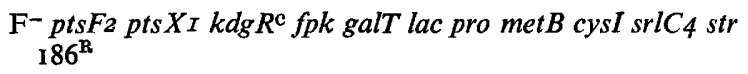 & JM794 (I 86 resistant) \\
\hline
\end{tabular}

The main purpose of this paper is to describe the properties of derivatives of ptsF pts $X$ strains, readily obtained by selecting phenotypic revertants to growth on 20 mu-fructose, that grow on this sugar because they effect its uptake and phosphorylation through a phosphotransferase normally used for sorbitol transport which, in these mutants, has become constitutive.

\section{METHODS}

The $E$. coli strains used in this work are listed in Table $I$ : their isolation or construction is indicated in Table $I$ or described in the text.

Organisms were grown on media and under conditions previously described (Ashworth \& Kornberg, 1966; Ferenci \& Kornberg, 1974). The genetical methods used were those compiled by Miller (1972).

The uptake of ${ }^{14} \mathrm{C}$-labelled substrates was measured as described by Ferenci \& Kornberg (1974). Sorbitol-6-phosphate dehydrogenase (EC. I. I. I. I40) was assayed by the method of Horwitz (1966).

D-Glucosaminitol borate ester was prepared by sodium borohydride reduction of $\mathrm{D}$ glucosamine. 


\section{RESULTS AND DISCUSSION}

\section{Evidence that the fructose-positive derivatives of strain $\mathrm{KLI} 6.2 \mathrm{I}$ are not revertants of $p t s X$ or ptsF}

From the Hfr strain KLI6.2I (ptsF pts $X k d g R^{\circ}$ ) that does not grow on $20 \mathrm{mM}$-fructose, numerous colonies that grew on plates containing $20 \mathrm{mM}$-fructose as sole carbon source were isolated. Of these, one (designated JM485), and four other independent isolates of the same phenotype, were mated with the $\mathrm{F}^{-}$strain $\mathrm{JM} 477$ ( $p t s F$ pts $X^{+}$kga str); $\mathrm{Kga}^{+}$recombinants were isolated on plates containing gluconate as sole carbon source, the donor organism being counter-selected by inclusion of streptomycin. Each of the crosses of the five mutants with the recipient strain yielded both $\mathrm{Kga}^{+}$recombinants that (like the parental organisms) grew on $20 \mathrm{~mm}$-fructose and others that (like the original strain KLI6.2I) did not. This showed that although the five Hfr mutants tested grew on $20 \mathrm{~mm}$-fructose, they still contained the pts $X$ marker and were able to transfer it to $p t s F p t s X^{+}$recipients to render these $p t s F p t s X$ and hence unable to utilize fructose.

Three kinds of explanation could account for the fructose-positive phenotype of strain JM485 and others like it. It might be that a second mutation within the $p t s F$ gene restored its catalytic activity but caused an increase in the $K_{\mathrm{m}}$ of the system for fructose. If so, and in the absence of PtsX function, fructose would be taken up and phosphorylated to fructose I-phosphate: the introduction of the $f p k$ gene (Fig. I) should then abolish utilization of fructose. This, however, is not the case. When the mutant JM485 was mated with strain JM486, which carries not only $p t s F$ and $p t s X$ but also $f p k$ (besides uhp pro cysI met $B$ galT str), 9 out of $\mathrm{I}_{20} \mathrm{Pro}^{+} \mathrm{Lac}^{+} \mathrm{Str}^{\mathrm{R}}$ recombinants tested grew on fructose and on glycerol, but growth on the latter substrate was inhibited by fructose I-phosphate. This showed that recombinants were able to take up the phosphate ester directly (and were thus Uhp ${ }^{c}$ ) but were devoid of fructose-I-phosphate kinase activity; the growth on fructose observed could therefore not have involved formation and catabolism of fructose I-phosphate, and hence could not have been achieved in consequence of an altered $p t s F$ gene. On the other hand, when one such fructose-positive recombinant was transduced with phage Pr propagated on an E. coli mutant devoid of fructose-6-phosphate kinase activity $(p f k)$ and $\mathrm{Met}^{+}$transductants were selected, a high proportion of such transductants failed to grow on fructose or mannitol. Since $p f k$ is known to be highly cotransducible with metB (Morrissey \& Fraenkel, 1969; Kornberg \& Smith, 1970), this result strongly indicates that fructose is utilized in these mutants via fructose 6-phosphate.

The cross between strains JM485 and JM486 that has been described also eliminates a second possible explanation for the growth of JM485 on fructose, namely that it is due to the presence of an amber suppressor mutation. Both the cysI and galT markers of the recipient strain JM486 are known to be due to amber mutations but many of the fructosepositive recombinants obtained from the cross with strain $\mathrm{JM}_{485}$ were either $\mathrm{Cys}^{-}$, or $\mathrm{Gal}^{-}$, or both.

A third possible explanation for the growth on fructose of mutants still carrying the $p t s F$ $p t s X$ genes is that this phenotype could arise by another type of translational suppression. However, mutants carrying pts $X 2$, an independently isolated allele of $p t s X$ different from the $p t s X I k d g R$ deletion carried by strain KLI6.2I and its derivatives (Jones-Mortimer \& Kornberg, 1976), were also suppressed by the gene that permitted $p t s X I$ mutants to grow on fructose. Thus a cross of strain JM485 (ptsFI pts XI kdgR Fructose ${ }^{+}$) and strain JM739 ( $p t s F I$ pts X2 leu str) gave Leu+ $\mathrm{Str}^{\mathrm{R}}$ recombinants, some of which had the donor phenotype for growth on fructose but did not grow on 2-keto-3-deoxygluconate: such recombinants had 
Table 2. Analysis of $\mathrm{Cys}^{+} \mathrm{Str}^{\mathrm{R}}$ exconjugants from an interrupted mating between strains

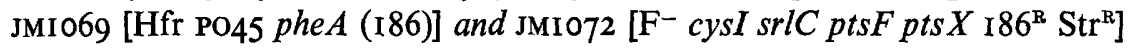

Recombinants were tested for their ability to grow with fructose as the carbon source, for their phenylalanine requirement and for being lysogenic for phage $\mathrm{I} 86$. If the gene order is cysI srlC att I86 phe $A$ then recombinants of classes $\mathrm{B}, \mathrm{D}, \mathrm{G}$ and $\mathrm{H}$ must arise from four crossings-over.

$\begin{array}{ccccc}\text { Class } & \text { Phenylalanine } & \text { Fructose } & \text { I86 } & \text { No. of recombinants } \\ \text { A } & - & - & + & 40 \\ \text { B } & - & - & - & 2 \\ \text { C } & + & + & - & 133 \\ \text { D } & + & + & + & \text { II } \\ \text { E } & + & - & + & 31 \\ \text { F } & + & - & - & 51 \\ \text { G } & - & + & - & 0 \\ \text { H } & - & + & + & \text { IO }\end{array}$

thus not inherited the $k d g R$ (Pouysségur \& Stoeber, 1974), and hence also not the $p t s X I$, allele. The ability of the suppressor to suppress the fructose negativity of such ptsFI pts X2 mutants is therefore not allele-specific; since it is also rather efficient, it is highly unlikely to be a translational suppressor. The mutation that confers ability to grow on fructose, via fructose 6-phosphate, on these ptsF pts $X$ strains must therefore represent a novel route of fructose utilization.

\section{Location of the lesion in ptsF pts $X$ strains which allows growth with fructose as the carbon source}

The mating described between strains JM485 and JM486 suggested that the lesion in JM485 might lie between the origin of the Hfr strain used (at min 55) and the pro and lac loci (at min 10 ) on the $E$. coli chromosome. Analysis of recombinants from interrupted conjugation of these two strains showed that 75 to $80 \%$ of the $c y s^{+}$recombinants selected within a few minutes of the beginning of mating had inherited the fructose-positive character of the donor strain, which suggested that the lesion is located close to cysI. This was confirmed by transduction. Bacteriophage PI was propagated on strains KLI6.2 I (ptsF pts $X$, Fructose-) and $\mathrm{JM}_{485}$ ( $p t s F$ pts $X$, Fructose ${ }^{+}$) and used to transduce the cysI strains JM760 (ptsF pts $X$, Fructose ${ }^{-}$) and JM486 ( $p t s F p t s X f p k$, Fructose ${ }^{-}$) respectively to $c y s I^{+}$. Of 128 recombinants from the first cross, Io ( $8 \%$ ) were fructose-negative, and of 536 recombinants from the second cross, $49(9 \%)$ were fructose-positive. Since we were unable to demonstrate cotransduction of the lesion with thy $A$ it is probable that the lesion is located at about min $5 \mathrm{I} \cdot 5$ rather than at min $53 \cdot 5$.

To test this conclusion, the Hfr strain JMI069 (pheA, lysogenic for phage 186) was mated with the fructose-positive strain JMI072 (cysI ptsF pts $X \mathrm{I}^{8} 6^{\mathrm{R}}$ ). Conjugation was interrupted I5 min after mixing and $c y s I^{+}$recombinants were selected on lactate minimal medium containing phenylalanine. These recombinants were scored for ability to grow on fructose, for phenylalanine requirement and for the inheritance of prophage. The results of this experiment (Table 2) indicate that the recombinant classes arising from four crossings-over are $\mathrm{B}, \mathrm{D}, \mathrm{G}$ and $\mathrm{H}$, so that the gene giving the Fructose ${ }^{+}$phenotype (which, as shown below, was identified as an altered regulatory gene of sorbitol uptake, srlC), is located between $c y s I$ and the integration site for phage 186 ; the gene order is therefore cysI srlC attI86 phe A. 


\section{Genetical evidence that the sorbitol phosphotransferase is involved in the utilization of fructose}

Epstein (cited in Taylor \& Trotter, 1972) and Lengeler (1975) showed that genes involved in sorbitol catabolism map between cysI and pheA. Since this is also the location of the mutation which allows pts $F$ pts $X$ mutants to grow on fructose, fructose might enter these cells via the sorbitol phosphotransferase. If this is so, two predictions can be made. Firstly, mutants that lack the sorbitol phosphotransferase $(s r l A)$ as well as the two fructose uptake systems ( $p t s F p t s X$ ) should not mutate to grow on fructose; secondly, srlA mutants selected in a fructose-positive ptsF pts $X$ strain should not be able to grow on fructose. Both these predictions have been borne out by experiments.

Strain JM759 ( $\left.f d a^{\text {ts }} p t s F p t s X\right)$ was isolated from strain JM737 ( $\left.f d a^{\text {ts }} p t s X\right)$ as a mutant that grew on glycerol at $4 \mathrm{I}{ }^{\circ} \mathrm{C}$ in the presence of fructose. Strains carrying the $f d a^{\text {ts }}$ marker are devoid of fructose-I,6-bisphosphate aldolase activity at $4 \mathrm{I}{ }^{\circ} \mathrm{C}$ but not at $30{ }^{\circ} \mathrm{C}$; the uptake and catabolism of fructose at the higher temperature thus leads to the formation and accumulation of fructose I,6-bisphosphate and growth stasis (Böck \& Neidhardt, 1966). Many of the mutants resistant to inhibition by fructose under these conditions (JonesMortimer \& Kornberg, 1976) owe this phenotype to the loss of fructose uptake system(s); since strain JM737 was already devoid of PtsX function, its derivative strain JM759 must also have lost PtsF activity. Like other ptsF pts $X$ mutants, strain JM759 does not grow on fructose at either 30 or $4 \mathrm{I}{ }^{\circ} \mathrm{C}$; however, it readily mutates to do so at the lower temperature. One such mutant able to grow on fructose at $30^{\circ} \mathrm{C}$ but not at $4 \mathrm{I}{ }^{\circ} \mathrm{C}$, and presumably $s r l C$, was designated JM78I. It was mutated further for loss of the gene for sorbitol uptake (srlA) in a manner analogous to that used for selection of $p t s F$ in a $f d a^{\text {ts }}$ background, by selecting mutants able to grow on glycerol at $4 \mathrm{I}^{\circ} \mathrm{C}$ in the presence of sorbitol. Strain JM784 is one such $f d a^{\text {ts }} p t s F$ pts $X$ srlC srlA derivative. It differs from its parent JM78I in being unable to grow on sorbitol and on fructose at $30^{\circ} \mathrm{C}$. This shows that the utilization of fructose by strain JM78I, which lacks the 'normal' systems for fructose uptake specified by $p t s F$ and $p t s X$ but is constitutive for sorbitol transport, occurs initially by sorbitol phosphotransferase.

This conclusion is reinforced by an experiment in which strain JM759 ( $f d a^{\text {ts }} p t s F p t s X$ ) was mutated to sorbitol resistance on glycerol at $4 \mathrm{I}{ }^{\circ} \mathrm{C}$; the mutant JM763 thus obtained was devoid of sorbitol phosphotransferase activity $(s r l A)$. In contrast to $s r l A^{+}$strains that carried $p t s F$ and $p t s X$, this srlA mutant did not give rise to any further mutants when plated on medium containing fructose as sole carbon source at $30^{\circ} \mathrm{C}$.

In order to establish that phosphotransferase activity was required for the function of the novel transport system for fructose, a mutant (JM803) was selected from strain JM78I ( $f d a^{\text {ts }}$ ptsF pts $X$ srlC) as a colony resistant at $4 \mathrm{I}{ }^{\circ} \mathrm{C}$ on lactate minimal medium simultaneously to both $N$-acetylglucosamine and mannitol: this mutant had lost the activity of Enzyme I of the phosphotransferase system ( $p t s I)$. In consequence, this strain ( $f d a^{t 8} p t s I$ ptsF pts $X$ srlC) did not grow on fructose at $30{ }^{\circ} \mathrm{C}$. This was not due to loss of the mutation $(s r l C)$ that had conferred on the parent strain JM78I the ability to grow on fructose since, when bateriophage PI propagated on strain JM803 was used to transduce strain JM486 ( $p t s F$ pts $X$ fpk cysI) to $\mathrm{Cys}^{+}, 8 \%$ of the transductants were fructose-positive. Mutants devoid of Enzyme I activity sometimes fail to grow on substrates that are not utilized via the phosphotransferase system as well as on substrates that are; this phenotype can be overcome by selecting further mutants that, whilst still devoid of Enzyme I activity, carry a $\mathrm{crr}$ gene highly cotransducible with ptsI (Saier \& Roseman, 1972; Jones-Mortimer \& Kornberg, 1975). When such crr 
Table 3. Uptake of fructose and sorbitol, and sorbitol-6-phosphate dehydrogenase activity, in strain KLI6.2I and its fructose-positive derivative strain $\mathrm{JM} 485$

The rates of uptake of ${ }^{14} \mathrm{C}$-labelled substrates by washed cells are expressed as $\mathrm{nmol}{ }^{14} \mathrm{C}$ incorporated $\min ^{-1}$ (mg dry mass) ${ }^{-1}$; sorbitol-6-phosphate dehydrogenase activity is expressed as $\mu$ mol NADH formed $\min ^{-1}$ (mg protein) ${ }^{-1}$.

\begin{tabular}{|c|c|c|c|c|c|c|}
\hline \multirow[b]{2}{*}{ Strain } & \multirow[b]{2}{*}{ Genotype } & \multirow[b]{2}{*}{ Grown on } & \multicolumn{3}{|c|}{ Uptake of } & \multirow{2}{*}{$\begin{array}{c}\text { Sorbitol- } \\
\text { 6-phosphate } \\
\text { dehydrogenase } \\
\text { activity }\end{array}$} \\
\hline & & & $\begin{array}{l}\text { O.I mM- } \\
\text { sorbitol }\end{array}$ & $\begin{array}{l}\text { O.I mM- } \\
\text { fructose }\end{array}$ & $\begin{array}{l}5 \mathrm{mM}- \\
\text { fructose }\end{array}$ & \\
\hline KLI6.2I & $p t s F p t s X$ & $\begin{array}{l}\text { Sorbitol } \\
\text { Glycerol }\end{array}$ & $\begin{array}{r}18 \\
2\end{array}$ & $\begin{array}{l}I \\
0 . I\end{array}$ & $\begin{array}{r}63 \\
5\end{array}$ & $\begin{array}{l}15 \\
0.5\end{array}$ \\
\hline JM485 & $p t s F p t s X$ srlCI & $\begin{array}{l}\text { Sorbitol } \\
\text { Glycerol } \\
\text { Fructose }\end{array}$ & $\begin{array}{l}18 \\
10 \\
\text { I } 2\end{array}$ & $\begin{array}{l}I \\
0 . I \\
0 . I\end{array}$ & $\begin{array}{l}26 \\
30 \\
35\end{array}$ & $\begin{array}{r}18 \\
4 \\
4\end{array}$ \\
\hline
\end{tabular}

mutants were selected from strain JM803 as colonies able to grow on maltose, they still failed to grown on fructose. We thus conclude that the growth of mutants of $p t s F p t s X$ strains on fructose requires an intact gene for sorbitol phosphotransferase and a functional Enzyme I. Consequently, fructose does not enter the cells as free fructose (by a system of active transport or of facilitated diffusion) subsequently to be phosphorylated by ATP in a reaction catalysed by a fructo(manno)kinase (Sebastian \& Asensio, 1967). The system of fructose utilization in these strains therefore also does not resemble that for galactose utilization in $m g l P$ galP Umg ${ }^{\circ}$ strains described by Kornberg \& Riordan (1976). However, the possibility of analogy with this system suggested that mutation to growth on fructose might be the result of constitutive synthesis of the sorbitol phosphotransferase rather than an alteration in its specificity. To test this hypothesis we isolated a mannitol-negative mutant (strain JMI058) from strain JM759 (by selection for mannitol resistance on glycerol at $4 \mathrm{I}{ }^{\circ} \mathrm{C}$ ). From strain JMr 058 sorbitol-constitutive mutants (Lengeler \& Lin, 1972) were selected on mannitol medium at $30{ }^{\circ} \mathrm{C}$. Since such $\mathrm{Mtl}^{+} \mathrm{Srl}^{\mathrm{c}}$ mutants have simultaneously acquired the ability to grow on fructose, we conclude that the suppression of the $\mathrm{Pts}^{-}$phenotype in ptsF ptsX mutants is the result of mutation in the regulatory system of the sorbitol phosphotransferase.

\section{Biochemical evidence that the sorbitol phosphotransferase is involved in the utilization of fructose}

If fructose can be utilized via the sorbitol phosphotransferase then pts $F$ pts $X$ cells in which this function has been induced should utilize fructose. To test this hypothesis, strains KLI6.2I ( $p t s F p t s X s r l C^{+}$) and JM485 ( $p t s F p t s X$ srlC) were grown overnight in minimal medium with either sorbitol or glycerol as the carbon source and were subcultured into minimal medium with either fructose as the carbon source or the original carbon source. Cultures of strain KLI6.2I that had been grown on glycerol did not adapt to grow on fructose, whereas those that had been grown on sorbitol grew on fructose, but at a rate that decreased with increase in cell mass: when plotted, this growth pattern was linear with time instead of exponential. In contrast, strain JM485 grew exponentially on fructose regardless of previous conditions of culture. The results obtained with strain KLI6.2 I suggest that fructose is a substrate for, but not an inducer of, the sorbitol phosphotransferase; the results for JM485 further suggest that this mutant, which grows on fructose, is constitutive for the sorbitol phosphotransferase.

We have therefore determined the activities of the sorbitol transport system in cells of various strains, and of the sorbitol-6-phosphate dehydrogenase in extracts of those cells, 
Table 4. Sorbitol-6-phosphate dehydrogenase activity in fructose-negative strains and their fructose-positive (sorbitol-constitutive) derivatives

Sorbitol-6-phosphate dehydrogenase activity is expressed as $\mu \mathrm{mol}$ NADH formed $\min ^{-1}$ (mg protein) $)^{-1}$.

\begin{tabular}{|c|c|c|c|c|}
\hline \multirow[b]{2}{*}{ Strain } & \multirow[b]{2}{*}{ Genotype } & \multirow{2}{*}{$\begin{array}{l}\text { Growth } \\
\text { temperature } \\
\left({ }^{\circ} \mathrm{C}\right)\end{array}$} & \multicolumn{2}{|c|}{ Grown on } \\
\hline & & & Glycerol & Sorbitol \\
\hline JM486 & $p t s F p t s X$ & $\begin{array}{l}37 \\
22\end{array}$ & $\begin{array}{l}0.33 \\
0.50\end{array}$ & $\begin{array}{l}7.8 \\
13\end{array}$ \\
\hline JM795 & $p t s F p t s X$ srlC 5 & $\begin{array}{l}37 \\
22\end{array}$ & $\begin{array}{l}2 \cdot 3 \\
0.68\end{array}$ & $\begin{array}{l}\text { I3 } \\
\text { II }\end{array}$ \\
\hline $\begin{array}{l}\text { JM794 } \\
\text { JM760 }\end{array}$ & $\begin{array}{l}\text { pts } F \text { pts } X \text { srlC4 } \\
\text { pts } F \text { pts } X \text { srlCz }\end{array}$ & $\begin{array}{l}37 \\
37\end{array}$ & $\begin{array}{l}8 \cdot 6 \\
I \cdot 5\end{array}$ & $\begin{array}{l}7 \cdot 5 \\
5 \cdot 0\end{array}$ \\
\hline $\begin{array}{l}\text { JM759 } \\
\text { JM78I }\end{array}$ & $\begin{array}{l}\text { pts } F \text { pts } X \\
\text { pts } F \text { pts } X \text { srlC3 }\end{array}$ & $\begin{array}{l}30 \\
30\end{array}$ & $\begin{array}{l}0.33 \\
7 \cdot 1\end{array}$ & $\begin{array}{l}5 \cdot I \\
6 \cdot 3\end{array}$ \\
\hline
\end{tabular}

obtained from cultures grown under inducing and non-inducing conditions. The results are summarized in Table 3. Strains such as JM485, predicted from the genetic evidence to be constitutive for the utilization of sorbitol, synthesize both the sorbitol uptake system and the dehydrogenase that acts on the product of sorbitol uptake and phosphorylation, in the absence of inducer.

\section{The nature of the control system}

Lengeler (1975) has shown that the constitutive allele of $s r l C$ (designated gutC by him) is cis dominant, since diploids of constitution $\mathrm{F}^{\prime} \mathrm{C}^{+} \mathrm{A}^{+} \mathrm{D}^{+} / \mathrm{C}^{\circ} \mathrm{A}^{-} \mathrm{D}^{-}$are mannitol-negative, whereas diploids of the type $\mathrm{F}^{\prime} \mathrm{C}^{+} \mathrm{A}^{+} \mathrm{D}^{+} / \mathrm{C}^{\mathrm{c}} \mathrm{A}^{+} \mathrm{D}^{+}$are mannitol-positive. This implies that the mutations to constitutivity are of the operator or initiator type. We have isolated a mutant, strain JM795, whose properties are indicated in Table 4. This strain grows exponentially on fructose at $37{ }^{\circ} \mathrm{C}$, albeit rather slowly, but does not grow at $22{ }^{\circ} \mathrm{C}$; growth on glycerol at either temperature is not impaired. The lesion in this strain $\left(\operatorname{srlC}_{5}\right)$ is $7 \cdot 3 \%$ cotransducible with $c y s I$, and therefore maps in the same region as other $s r l C$ mutants. If it is a mutation of the same type as those described by Lengeler (1975), the strain must either have a temperature-sensitive operator (which cannot recognize the repressor at $37^{\circ} \mathrm{C}$, but can do so at $22{ }^{\circ} \mathrm{C}$ ) or a cold-sensitive initiator. It seems more plausible that the mutation is of a different type, resembling the thermosensitive lacI mutants described by Sadler \& Novick (1965) in being a temperature-sensitive mutant in a negative control gene. This view is supported by the rate of spontaneous mutation of pts $F p t s X$ strains to $s r l C$, which is of the order of $10^{-7}$ per cell per generation, a value which would appear to be too high for the rather specific base changes required to produce an operator-constitutive mutant or any kind of constitutive mutant in a positive control system.

\section{Specificity of the sorbitol uptake system}

The utilization of fructose that can occur through its uptake and phosphorylation by the sorbitol phosphotransferase if that activity is first induced (Fig. I) also shows that the stereochemical requirements for phosphotransferase induction are more stringent than those exhibited by its activity. This supports the findings of Lengeler \& Lin (1972) and Lengeler (1975) who showed that sorbitol, mannitol and 2-deoxyarabinohexitol are substrates for the sorbitol phosphotransferase, but, of these, only sorbitol is an inducer of the system. We have 


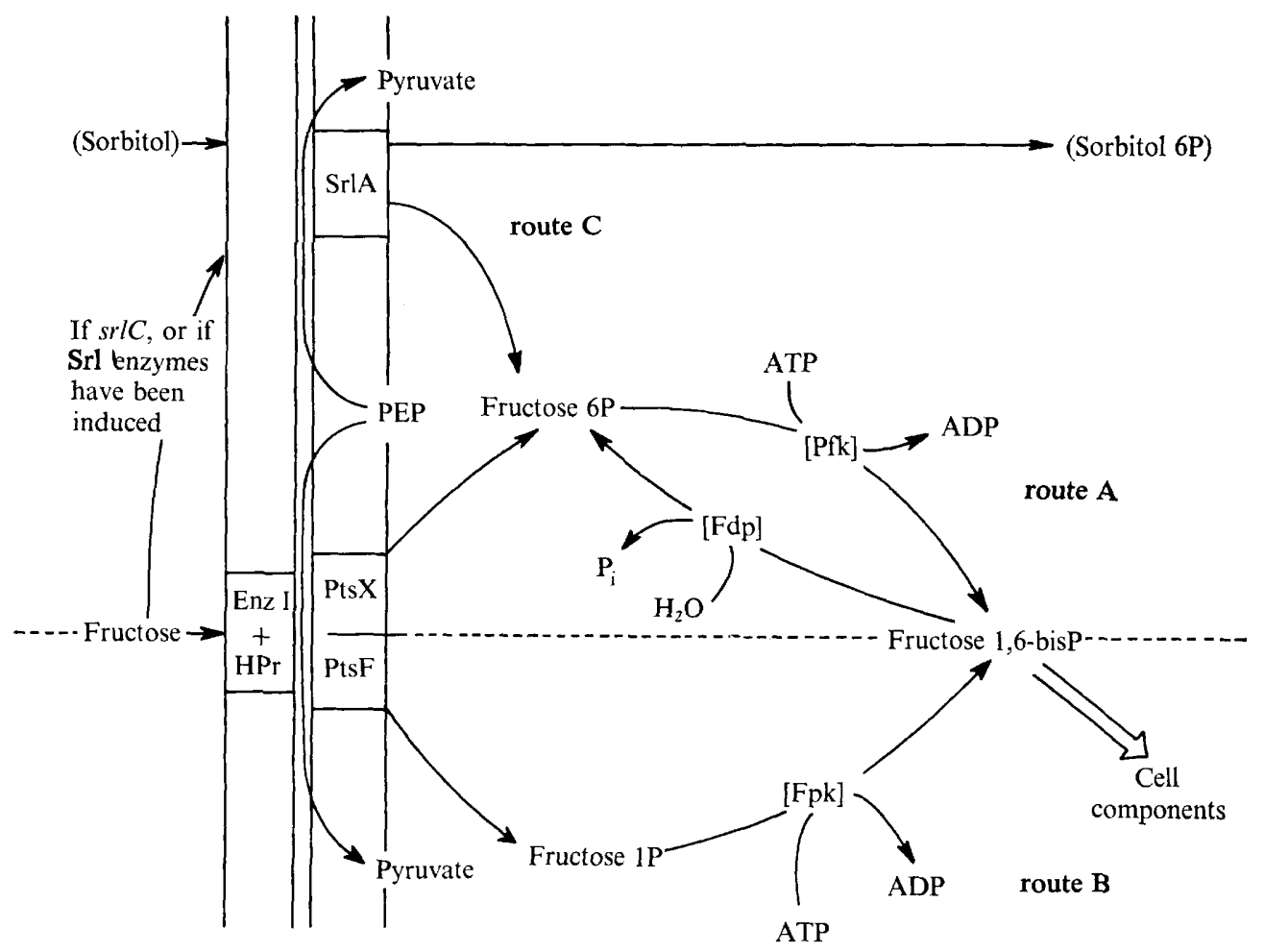

Fig. I. Postulated pathway of fructose utilization in $p t_{s} F p t s X$ mutants in which the enzymes of sorbitol uptake and catabolism have been induced.

shown above that fructose is a substrate for the system but not an inducer. No uptake of glucose could be demonstrated in $E$. coli strains which lack all the known systems for glucose transport (Kornberg \& Jones-Mortimer, 1974) but which are constitutive for the sorbitol phosphotransferase. Furthermore, mutants which are inducible for the sorbitol phosphotransferase are not inhibited by glucosaminitol during growth on glycerol, whereas mutants which are constitutive for the system are sensitive, but give rise to resistant clones which have lost the ability to grow on sorbitol. It therefore appears that a hydroxyl group on the $\mathrm{C}-\mathrm{I}$ atom is essential for transport by this system, but that, though the nature of the groups attached to the C-2 atom is relatively unimportant in this respect, a hydroxyl group in the D-gluco configuration at $\mathrm{C}-2$ is essential for induction.

We are grateful to Drs B. Bachmann and R. A. Cooper for providing strains of bacteria, to Drs F. Jacob and M. D. Yudkin for strains of bacteriophage, and to Mr J. W. Keyte for technical assistance. We also gratefully acknowledge the support received from the Science Research Council and The Royal Society through research grants. 


\section{REFERENCES}

ASHWORTH, J. M. \& KoRNBERG, H. L. (I966). The anaplerotic fixation of carbon dioxide by Escherichia coli. Proceedings of the Royal Society B $165,179-188$.

Böck, A. \& NeIDHARDT, F. C. (I966). Isolation of a mutant of Escherichia coli with a temperature-sensitive fructose I,6-diphosphate aldolase activity. Journal of Bacteriology 92, 464-469.

CuRTIS, S. J. \& EPSTEIN, W. (1975). Phosphorylation of D-glucose in Escherichia coli mutants defective in glucose phosphotransferase, mannose phosphotransferase and glucokinase. Journal of Bacteriology 122, I I 89-I I 99.

Ferenci, T. \& Kornberg, H. L. (197I). Pathway of fructose utilization by Escherichia coli. FEBS Letters I3, $127-130$.

Ferenci, T. \& Kornberg, H. L. (1974). The role of phosphotransferase-mediated syntheses of fructose I-phosphate and fructose 6-phosphate in the growth of Escherichia coli on fructose. Proceedings of the Royal Society B 187, 105-I 19.

FraENKel, D. G. (I968). The phosphoenolpyruvate-initiated pathway of fructose metabolism in Escherichia coli. Journal of Biological Chemistry 243, 6458-6463.

Hoekstra, W. P. M., Storm, P. K. \& ZuidWeig, E. M. (1974). Recombination in Escherichia coli. VI. Characterization of a recombination-deficient mutation with unusual properties. Mutation Research $\mathbf{2 3}$, 319-326.

HorwITZ, S. B. (I966). D-Mannitol 1-phosphate dehydrogenase and D-sorbitol 6-phosphate dehydrogenase from Aerobacter aerogenes. Methods in Enzymology 9, 150-155.

Jones-Mortimer, M. C. \& Kornberg, H. L. (1974). Genetical analysis of fructose utilization by Escherichia coli. Proceedings of the Royal Society B 187, I2 I-13I.

Jones-Mortimer, M. C. \& Kornberg, H. L. (1975). Genetic control of inducer exclusion by Escherichia coli. FEBS Letters $48,93-95$.

Jones-Mortimer, M. C. \& Kornberg, H. L. (I976). Order of genes adjacent to pts $X$ on the $E$. coli genome. Proceedings of the Royal Society B I93, 313-315.

KORNBERG, H. L. (1972). Nature and regulation of hexose uptake by Escherichia coli. In The Molecular Basis of Biological Transport, pp. 157-180. Edited by J. F. Woessner and F. Huijing. New York and London: Academic Press.

Kornberg, H. L. \& Jones-Mortimer, M. C. (1974). Pts X: a gene involved in the uptake of glucose and fructose by Escherichia coli. FEBS Letters 51, I-4.

KORNBERG, H. L. \& RIORDAN, C. L. (I976). Uptake of galactose into Escherichia coli by facilitated diffusion. Journal of General Microbiology 94, 75-89.

Kornberg, H. L. \& SMITH, J. (1970). Role of phosphofructokinase in the utilization of glucose by Escherichia coli. Nature, London 227, 44-46.

Kundig, W., Ghosh, S. \& Roseman, S. (1964). Phosphate bound to histidine in a protein as an intermediate in a novel phosphotransferase system. Proceedings of the National Academy of Sciences of the United States of America 52, 1067-1074.

LENGELER, J. (1975). Mutations affecting transport of the hexitols D-mannitol, D-glucitol and galactitol in Escherichia coli $\mathrm{K} 12$ : isolation and mapping. Journal of Bacteriology 124, 26-38.

LENGELER, J. \& LIN, E. C. C. (1972). Reversal of the mannitol-sorbitol diauxie in Escherichia coli. Journal of Bacteriology 112, 840-848.

Miller, J. H. (1972). Experiments in Molecular Genetics. New York: Cold Spring Harbor Laboratory.

Morrissey, A. T. E. \& Fraenkel, D. G. (1969). Chromosomal location of a gene for fructose 6-phosphate kinase in Escherichia coli. Journal of Bacteriology 100, I I08-I 109.

Pouysségur, J.-M. \& Stoeber, F. (1974). Genetic control of the 2-keto-3-deoxy-D-gluconate metabolism in Escherichia coli: $k d g$ regulon. Journal of Bacteriology $117,64 \mathrm{I}-659$.

SADLER, J. R. \& Novick, A. (1965). The properties of repressor and the kinetics of its action. Journal of Molecular Biology 12, 305-327.

SAIER, M. H. \& RosEMAN, S. (1972). Inducer exclusion and repression of enzyme synthesis in mutants of Salmonella typhimurium defective in Enzyme I of the phosphoenolpyruvate:sugar phosphotransferase system. Journal of Biological Chemistry 247, 972-975.

Sebastian, J. \& Asensio, C. (1967). Identification of a mannokinase in Escherichia coli. Biochemical and Biophysical Research Communications 28, 197-202.

TAYLOR, A. L. \& TROTTER, C. D. (1972). Linkage map of Escherichia coli strain KI2. Bacteriological Reviews 36, 504-524. 